\title{
Structure of Metal Oxide Multilayers Deposited by Sol-Gel Method on Surface of NiTi Shape Memory Alloy
}

\author{
P. $\operatorname{OSAK}^{a}$, J. WAS $\bar{S}^{b}$ AND B. $\operatorname{LOSIEWICZ}^{a, *}$ \\ ${ }^{a}$ Institute of Materials Science, University of Silesia, 75 Pułku Piechoty 1A, 41-500 Chorzów, Poland \\ ${ }^{b}$ BOSMAL Automotive Research and Development Institute, Bielsko-Biała, Poland
}

\begin{abstract}
The metal oxide layers were deposited onto the surface of NiTi shape memory alloy using sol-gel method. Single-, double- and triple-layers were obtained from a colloidal solution containing the precursor of zirconium tetrabutoxide and titanium tetrabutoxide, and annealed at $300^{\circ} \mathrm{C}$ for $1 \mathrm{~h}$ in argon. Phase composition was determined by grazing incidence X-ray diffraction. Surface roughness of the metal oxide layers were determined by atomic force microscopy. Surface morphology and thickness of the obtained layers were studied by scanning electron microscopy. It was found that all obtained layers revealed a composite structure, and were characterized by low surface roughness and thickness parameters. A homogeneous structure of the metal oxide layers deposited onto the surface of the medical NiTi alloy was ascertained only for double- and triple-layers.
\end{abstract}

DOI: 10.12693/APhysPolA.130.1069

PACS/topics: $78.40 . \mathrm{Kc}, 81.20 . \mathrm{Fw}, 62.20 . \mathrm{fg}$

\section{Introduction}

Titanium and its alloys are materials widely used in medicine, most often in orthopaedics and orthodontics. Particularly popular are NiTi shape memory alloys which belong to a group of intelligent materials characterized by such properties as one- and two-way shape memory effect and pseudoelasticity. A physical phenomenon inducing shape memory effect is thermoelastic and reversible martensitic transformation. This transformation takes place between the high-temperature phase centered cubic spatially parent type $B 2$, and the low temperature martensite phase monoclinic $B 19^{\prime}$ type of network [1]. The NiTi alloys with a composition close to equiatomic show very good mechanical properties and high biocompatibility [2]. The NiTi implant alloys have a high corrosion resistance due to the spontaneous formation on the surface of oxide layer. However, the use of NiTi alloys for long-term implants raises many fears mainly connected with high nickel content. Trace amounts of nickel are essential for the body, but its excessive content has a negative effect on the tissues surrounding the implant, causing a number of toxic reactions, such as allergies or metalosis [3]. Therefore, it is crucial to modify the surface of this alloy in order to improve its biocompatibility and corrosion resistance. Therefore, this work was undertaken in order to produce and characterize the metal oxide multilayers onto the surface of the NiTi alloy using sol-gel method for the first time.

\section{Experimental}

As a substrate material flat specimens of $\mathrm{NiTi}$ alloy (50.6 at.\% Ni) with dimensions of $15 \times 10 \times 0.8 \mathrm{~mm}^{3}$, manufactured by AMT (Belgium), were used. Preparation of the surface of samples before deposition of

*corresponding author; e-mail: bozena.losiewicz@us.edu.pl the coating was described in detail in the previous works [1-3]. The characteristic temperatures of the martensitic transformation were determined from differential scanning calorimetry (DSC) using a Perkin-Elmer Differential Scanning Calorimeter DSC 7 in liquid nitrogen atmosphere, at a temperature from $-120^{\circ} \mathrm{C}$ to $80^{\circ} \mathrm{C}$.

\section{TABLE I}

The chemical composition of the sol.

\begin{tabular}{c|c}
\hline \hline Element & $\begin{array}{c}\text { Molar } \\
\text { concentration }\end{array}$ \\
\hline $\mathrm{ZrBu}$ & 1 \\
$\mathrm{TiBu}$ & 1 \\
$\mathrm{CH}_{3}\left(\mathrm{CH}_{2}\right)_{3} \mathrm{OH}$ & 7 \\
$\mathrm{CH}_{3} \mathrm{COOH}$ & 0.15 \\
$\mathrm{HNO}_{3}$ & 0.15
\end{tabular}

The surface of NiTi shape memory alloy was modified by deposition of metal oxide layers using sol-gel method (the home-made device). Ceramic layers were deposited by immersion into the colloidal solution containing the precursor of zirconium $\mathrm{ZrBu}$ and $\mathrm{TiBu}$ (Table I). The steps for preparing metal oxide sol are shown in Fig. 1. Single-, double- and triple layers were deposited onto the surface of NiTi alloy. Next, the layers obtained by the sol-gel method were annealed at $300^{\circ} \mathrm{C}$ for $1 \mathrm{~h}$ in argon.

Phase composition was confirmed by grazing incidence X-ray diffraction (GIXRD) on the X'Pert Philips PW $3040 / 60$ diffractometer operating at $30 \mathrm{~mA}$ and $40 \mathrm{kV}$, which was equipped with a vertical goniometer and an Eulerian cradle, respectively. The wavelength of radiation $\left(\lambda\left(\mathrm{Cu} K_{\alpha}\right)\right)$ was $1.54178 \AA$. The GIXRD patterns were registered in the $2 \theta$ range from $10^{\circ}$ to $50^{\circ}$ with a $0.05^{\circ}$ step for the incident angle: $0.25^{\circ}, 0.50^{\circ}$ and $1.00^{\circ}$, $1.50^{\circ}$. The roughness of the layers was determined by 


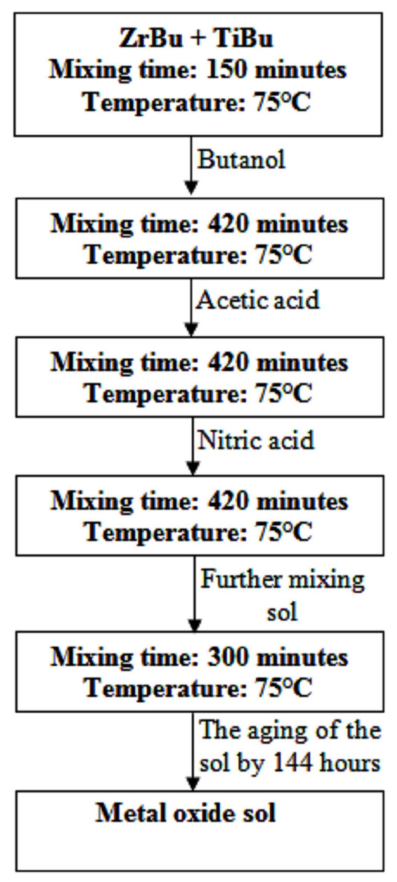

Fig. 1. The steps for preparing sol.

atomic force microscopy (AFM, Hysitron TI 950) while the surface morphology and thickness were studied by scanning electron microscopy (SEM, JEOL JSM-6480).

\section{Results and discussion}

The thermogram registered for the NiTi alloy is pictured in Fig. 2. The results obtained from DSC measurements show that the characteristic temperatures of the martensitic transformation are as follows: $M_{\mathrm{s}}=-16^{\circ} \mathrm{C}$, $M_{\mathrm{f}}=-30^{\circ} \mathrm{C}, A_{\mathrm{s}}=-2^{\circ} \mathrm{C}, A_{\mathrm{f}}=10^{\circ} \mathrm{C}$.

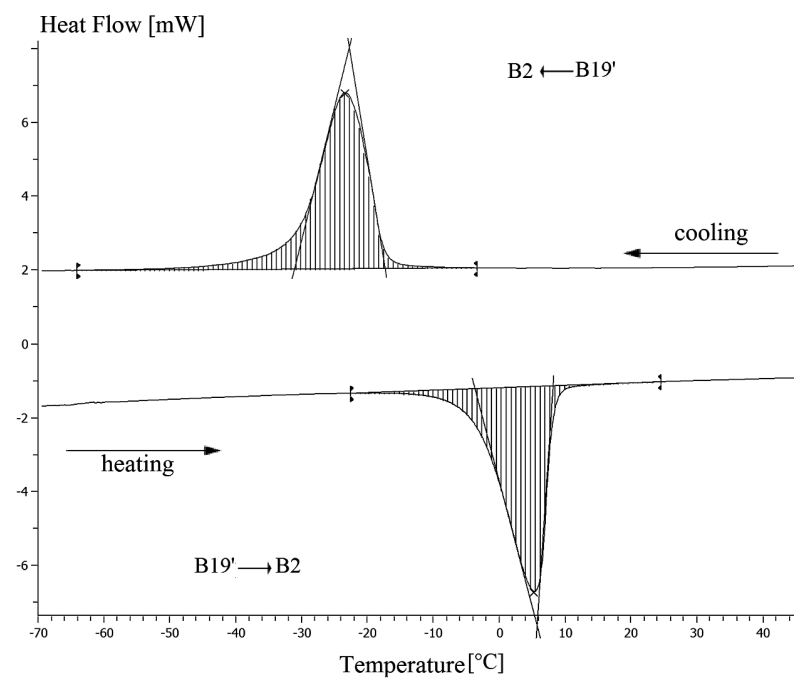

Fig. 2. Thermograms registered for the NiTi alloy.

The GIXRD phase identification of the metal oxide layer on the NiTi substrate (Fig. 3) revealed the presence of the following phases: $\mathrm{Zr}_{0.1} \mathrm{Ti}_{0.9} \mathrm{Ni}_{3}$ (ICDD PDF 04001-5453), $\mathrm{TiO}_{2}$ rutile (ICDD PDF 00-001-1292), NiTi (ICDD PDF 01-078-4618) and $\mathrm{Ni}_{2} \mathrm{Ti}$ (ICDD PDF 01072-2619).

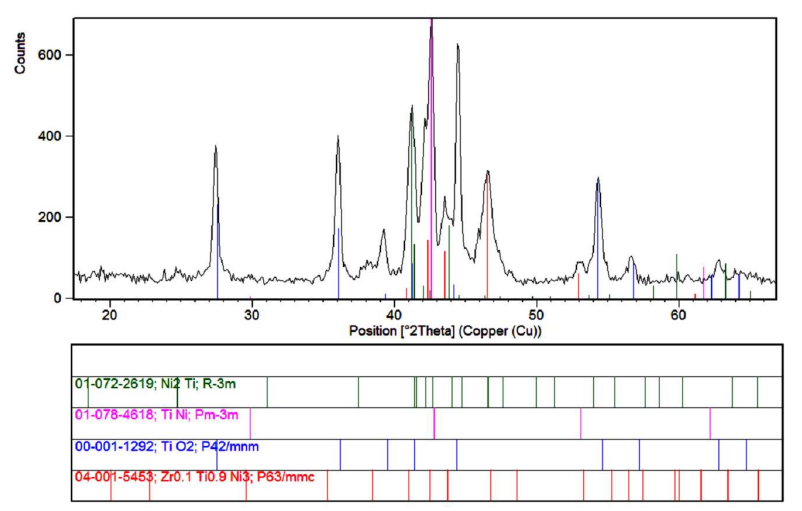

Fig. 3. GIXRD pattern for the NiTi alloy coated by metal oxide double-layer at $\alpha=1.00^{\circ}$.

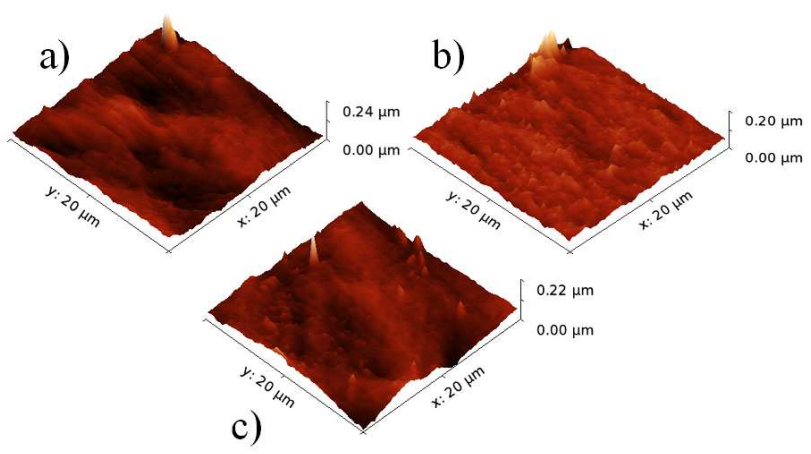

Fig. 4. AFM images of the surface of NiTi alloy coated with metal oxide: single-layer (a), double-layer (b), and triple-layer (c).

Figure 4 shows AFM images of the surface of NiTi alloy coated with metal oxide single-layer (a), double-layer (b), and triple-layer (c). Parameters of roughness and thickness determined by AFM and SEM, respectively, for the $\mathrm{NiTi}$ alloy coated with metal oxide layers are shown in Table II.

TABLE II

Roughness calculated for the area of $20 \times 20 \mu \mathrm{m}^{2}$ and thickness for the NiTi alloy coated with metal oxide layers.

\begin{tabular}{c|c|c|c}
\hline \hline No & $\begin{array}{c}\text { Metal oxide } \\
\text { layer }\end{array}$ & $\begin{array}{c}\text { Roughness } \\
R_{\mathrm{A}}[\mu \mathrm{m}]\end{array}$ & $\begin{array}{c}\text { Thickness } \\
{[\mathrm{nm}]}\end{array}$ \\
\hline 1 & single & $2.9 \pm 0.1$ & $180 \pm 10$ \\
2 & double & $4.0 \pm 0.1$ & $200 \pm 11$ \\
3 & triple & $4.7 \pm 0.1$ & $350 \pm 17$
\end{tabular}

Figures 5 and 6 (inset) show SEM images of the surface of NiTi alloy coated with metal oxide, and corresponding energy dispersive X-ray spectrometry (EDS) analysis. 
Table III presents atomic composition for the NiTi alloy with metal oxide layers.

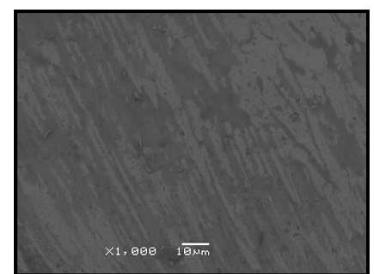

a)

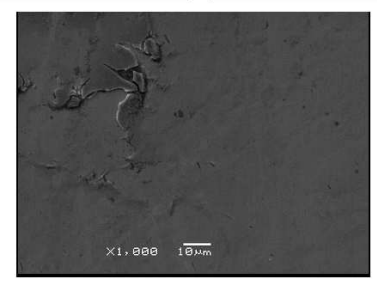

Fig. 5. SEM images of the surface NiTi alloy with metal oxide for single-layer (a), double-layers (b) and triple-layers (c).

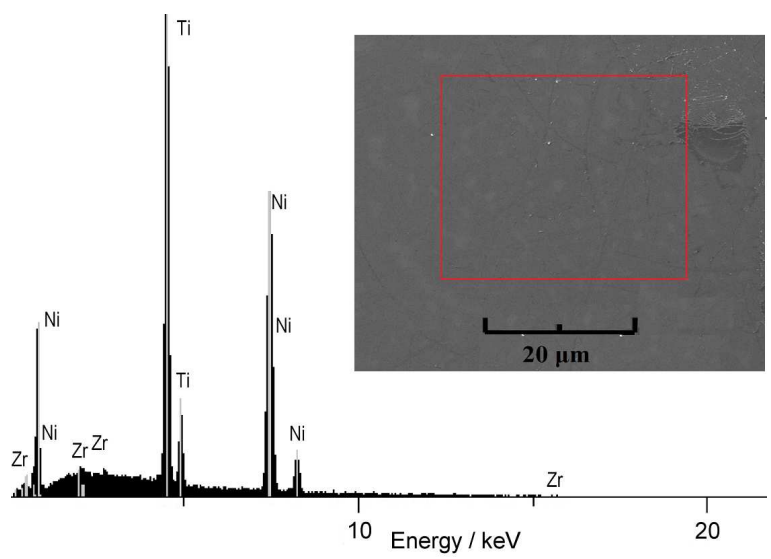

Fig. 6. EDS analysis of the NiTi alloy with metal oxide double-layer.
TABLE III

Atomic composition of the NiTi alloy with metal oxide layers.

\begin{tabular}{c|c|c|c|c|c}
\hline \hline & Oxide & \multicolumn{4}{|c}{ Element [at.\%] } \\
\cline { 3 - 6 } No & layer & $\mathrm{O}$ & $\mathrm{Ti}$ & $\mathrm{Ni}$ & $\mathrm{Zr}$ \\
\hline 1 & single & $10.5 \pm 0.7$ & $42.5 \pm 1.2$ & $40.8 \pm 0.9$ & $6.2 \pm 0.2$ \\
2 & double & $13.3 \pm 0.6$ & $36.4 \pm 2.3$ & $38.2 \pm 2.4$ & $12.1 \pm 0.4$ \\
3 & triple & $13.6 \pm 0.6$ & $39.1 \pm 4.4$ & $34.3 \pm 3.1$ & $13.0 \pm 0.8$
\end{tabular}

\section{Conclusion}

The EDS, SEM, AFM and GIXRD studies confirmed the possibility of deposition of metal oxide layers on NiTi alloy using sol-gel method. The obtained composite coatings were characterized by low values of roughness $\left(R_{\mathrm{A}}=2.9 \mu \mathrm{m}\right.$ for single-layer, $R_{\mathrm{A}}=4.0 \mu \mathrm{m}$ for double-layer, and $R_{\mathrm{A}}=4.7 \mu \mathrm{m}$ for triple-layer), and revealed a homogeneous morphology in case of double- and triple-layers. Phase analysis confirmed the presence of phase: $\mathrm{Zr}_{0.1} \mathrm{Ti}_{0.9} \mathrm{Ni}_{3}, \mathrm{TiO}_{2}, \mathrm{NiTi}$, and $\mathrm{Ni}_{2} \mathrm{Ti}$. The thickness of single-, double- and triple-layer was 180, 200, and $350 \mathrm{~nm}$, respectively.

Production of metal oxide layers by sol-gel method allows to get a new generation of biomaterials with strictly defined microstructure, phase and chemical composition as well as surface topography acting modern technology in the field of biomaterials.

\section{References}

[1] J. Lelątko, T. Goryczka, T. Wierzchoń, M. Ossowski, B. Łosiewicz, E. Rówiński, H. Morawiec, Solid State Phenom. 163, 127 (2010).

[2] P. Osak, B. Łosiewicz, T. Goryczka, Solid State Phenom. 227, 443 (2015).

[3] M. Freitag, B. Łosiewicz, T. Goryczka, J. Lelątko, Solid State Phenom. 183, 57 (2012). 